\title{
An Intersectional Analysis of Urban Public Interiors
}

\author{
KARIN I. TEHVE \\ Pratt Institute
}

This paper proposes an analysis of New York City's Interior Privately owned Public Spaces (INT POPS) and the quality of public space they generate. Intersectionality here is a methodology to examine key attributes of INT POPS simultaneously. This method offers opportunities to question prevailing typologies of the term public that are oppositional in nature; this opposition serves to occlude the mutually dependent nature of the types. INT POPS are vaguely programmed, bounded, enclosed and enable proximity, and generate a social space recognizable as an essential characteristic of urban life: a visible aggregation of individuals prior to definition as a collective. Without a simultaneous examination of the physical spaces themselves and the rules, laws and codes that govern them these spaces a false image of a universally accessible space is produced.

\section{INTRODUCTION}

At first glance, the terms "public" and "interior" suggest an essential opposition. Any bounded space has a set of conditions or rules for entry and create categories of those who are in or out. This paper proposes an intersectional analysis of a particularly quixotic hybrid: the interior privately-owned public spaces (INT POPS ${ }^{1}$ ) of New York City. Intersectionality ${ }^{2}$, as a method, proposes the simultaneous consideration of characteristics, often previously considered discretely, in order to excavate the relationships of multiple factors simultaneously regarding a subject's nature. This method offers novel opportunities to examine definitions of public especially in regard to interior spaces, and questions whether the commonly oppositional natures of those definitions serve to veil useful subtleties. An examination of INT POPS reveals characteristics of occupation and form that when considered simultaneously, reveal the generation of a specific type of urban space, while keeping in mind that any benefits engendered there must be examined in a broader context. Existing critiques of INT POPS should too be understood in aggregate, as complex as the populations they are to serve.

\section{HISTORY AND BACKGROUND}

In the 1960's, New York City introduced a zoning resolution (also known as incentive zoning) that offered private developers the ability to add area and height to building projects in exchange for space given back to its citizens. Between 1961 and 2000 , millions of square feet beyond allowable FAR were constructed in exchange for over 500 public spaces. These spaces are now known as POPS (privately owned public spaces)- owned, managed and maintained by the developer or building owner, open for use by the public.
Most NYC POPS are in the dense primarily commercial neighborhood of Midtown Manhattan. POPS include exterior plazas, arcades and dozens of interior spaces. The NYC Zoning Resolution defined each POPS as a type: urban plaza, sidewalk widening, through block galleria. As is typical of zoning language, descriptions of these spaces were broad, outlining minimum dimensions, proportions, and degrees of enclosure. Their means were empirically defined, but their ends were abstractly performative. The most clearly defined goals, as described in the zoning language, for the spaces were as extensions and expansions of sidewalks as a relief to pedestrian congestion, at the edges of or through the centers of city blocks.

Types that support seating (suggesting program beyond movement) are also broadly described; for example, a Covered Pedestrian Space is specified to be directly accessible from streets or other parts of pedestrian ways, its entries should be unobstructed, and should be used as a connector between public ways when feasible. The stated goal: ....a sheltered space for the comfort and convenience of the general public ${ }^{3}$. The nature of the public to be created is not explicitly stated.

Amended over time ${ }^{4}$, the language of the resolution expanded to include specific physical characteristics. Early updates included specifications for limits to changes in elevation, relationship to the ground plane and visibility. Later, language was added to include requirements more specific requirements for features and amenities such as seating and landscaping.

The life of these spaces has been exhaustively documented by Jerold S. Kayden, a professor at Harvard University and founder of "Advocates for Privately Owned Public Space." His research included field surveys conducted in the late 1990 's that revealed roughly 50 percent of all POPS did not conform to the applicable guidelines defining access to these spaces. The documentation Kayden refers includes not only the Zoning Resolution itself, but myriad legal instruments and documents that codify the construction and administration of said spaces ${ }^{5}$. In his writing, Kayden defines the public generated by POPS primarily in legal terms- in opposition to both public property (as it is not owned by the City) and private property to which the owner grants public access, programs including retail and hospitality ${ }^{6}$

Neither the language of the zoning documentation nor Kayden's extensive analysis define parameters for the social or political purpose of these spaces. It may be that 
the ambiguity of goals regarding the definitions of INT POPS stems from the broad terrain covered by the term itself, that clear criteria for a given public is elusive.

\section{PUBLIC SPHERE> PUBLIC SPACE}

Kristine Miller succinctly defines a public space as the intersection of a physical space with the public sphere ${ }^{7}$; the public sphere refers to the immaterial, forming in communication and interpersonal engagement. One description of the public sphere involves the praxis protected under the US Constitution's First Amendment. In addition to protecting rights to freedom of religion, the First Amendment allows individuals to express themselves without government interference and to peaceably assemble; it specifically declares the freedom to petition the Government for a redress of grievances ${ }^{8}$. This outlines the rights necessary to protect political protest, the citizenry protected as individuals and as groups against the interference of the state in order to address that state. Under these conditions, INT POPS could not be considered public, in that political protest would generally not be permitted in interiors; First Amendment protections are for the most part ${ }^{9}$ restricted to traditional public forums: parks, sidewalks and other exterior spaces.

There is abundant scholarship regarding the formation of a public sphere; perhaps the most clearly delineated is the space of appearance, a term Hannah Arendt uses to describe the conditions created through the unrestricted discourse between equals. The space of appearance is generated by action, which, according to Arendt, is meaningless without the presence of others. Action requires appearing in public and making oneself known though discourse with one's peers, the basis simultaneously for an individual's identity and all political life. Action requires plurality, the ability to acknowledge and construct a unique relationship between each free subject, each acknowledged to have an independent perspective ${ }^{10}$. Arendt does not describe the specific sensible qualities of the physical spaces in which action could be realized, but implicit in her descriptions is the prerogative of common embodied access; action can only be realized in a face-to-face, unmediated relation between subjects.

What is privileged in these descriptions of public are descriptions of the conditions enabling collective action, defining a political body of citizenry in opposition to a representative body. The clarity and focus of both definitions occlude other potential definitions; certainly under these conditions, INT POPS could not be considered public. Beyond the lack of First Amendment protections, INT POPS are further problematized in the display of plaques affixed to walls outlining rules of conduct for its occupants. Doug Woodward suggests these rules restrict occupation to narrowly defined passive uses ${ }^{11}$. For Arendt, any rules that create hierarchies of empowerment nullify the possibility of unconstrained discussion and debate; the mediation of posted rules precludes an Arendtian public ${ }^{12}$.
Using Arendt's system of classification of models of engagement, INT POPS would produce what she refers to as social space, discrete to the space of appearance. Social space borrows its structure from the intimate sphere, in that power is distributed hierarchically, making discourse rule-bound and constrained as in a family before the despotic rules of the household head ${ }^{13}$. Home, in this formulation, was the sphere of emotions and intimacy, conditions that must be invisible from any conception of the public in order to for either to thrive; the intimate made the public possible. Arendt acknowledges that in her model of the Greek polis, only free land-owning men had access to public life. If the intimate sphere of the household were visible, it would reveal the women, children and slaves absent from the autonomous spaces of democracy and expressions of free will ${ }^{14}$.

It was Arendt's position that the social was modernity's collective condition, where common interest and unanimous opinion emphasized conformity. Arendt mourned the loss of individual difference as realized by action, suggesting that distinction had become a condition of the private realm, depriving citizens of essential components of their own identity and humanity ${ }^{15}$

Arendt's radicalized oppositions between public and private are devices that lend clarity to the definition of a public sphere but arguably exclude entire modalities of human collective endeavor, including the sphere of commerce ${ }^{16}$. INT POPS might be considered to be akin to Sola-Morales' terrain vague; in both Arendt's model and US Constitutional protections, INT POPS are exterior to the public life of the city, undefined in their inability to support the collective political action that constructs it.

INT POPS foster anonymity in the company of strangers, a defining characteristic of urban life. It is in this imprecise inbetween that it is possible to create visible and embodied aggregations of individuals prior to definition as a political body. A simultaneous examination of physical characteristics INT POPS have in common and the social praxis they support reveals a unique mediator between spaces of appearance and invisibility in their identities as domains of wide gradients of sociability and interaction between the private and public.

\section{INT POPS: ENCLOSED}

INT POP typologies are varied, including Through Block Galleria, Atria, and the aforementioned Covered Pedestrian Space. Combinations of and variances diverging from defined types were common, allowing responses to unique and heterogeneous conditions of site. While specifics regarding dimension, visibility and required amenities vary per type, each INT POPS shares the condition of enclosure, providing shelter from the elements, within a larger system of spaces supporting both movement and stasis. INT POPS construct the possibility of pause and place within the routes and 
networks which link up the places set aside for work, 'private' life and leisure ${ }^{17}$ evoking Lefebvre's spatial practice by which an urban subject negotiates daily life and a broader urban reality. INT POPS, in contrast to exterior spaces, support visits of longer duration than exterior spaces, independent of weather. Duration expands the pool of potential inhabitantsfrom the passer-by on a unique trajectory, to those for whom habit or routine make a space a regular destination.

In a lecture delivered at Harvard's Graduate School of Design in 2016, Richard Sennett discussed Interiors and Interiority. Sennett suggests that an urban public interior provides an escape from the tyranny of the sphere of family and its intimate authority, an account recalling Arendt's description of the domestic sphere. His assertion is that adoption of a blasé comportment (as described by Georg Simmel in The Metropolis and Mental Life) enhanced the condition of anonymity. A face composed to blankness veils both the content and existence of one's private thoughts. This privacy-in public is a particularly urban sensibility, according to Sennett, providing an opportunity to develop an identity independent of the scrutiny of those with strong ties ${ }^{18}$, an issue particularly salient to women and other victims of repressive familial structures.

\section{INT POPS: ENABLE PROXIMITY}

When INT POPS support destination functions, seating is specified, usually a combination of fixed benches and movable tables and chairs. Benches usually line circulation zones; tables and chairs tend to be laid out in grids, roughly conforming to the 54" o.c. dimension of hospitality space planning. This furniture is made familiar through its standardization, a democracy of identical chairs, imparting a sameness across the potential diversity of its inhabitants. Seating logically supports the project of duration, and demarcating spaces for individuals within the aforementioned aggregation of strangers. This a condition Guy Debord dismisses as characteristic of the social life of late capitalism, a tranquil side-by-sideness ${ }^{19}$. It is of course possible to suggest that the appearance of tranquility (or a blasé comportment) masks active, even difficult operations of interiority made possible by proximity, stillness and duration. Ignasi de Solà-Morales describes internal struggle of all urban inhabitants to reconcile a unified sense of self with the presence of the other ${ }^{20}$.

Proximity enables close observation of one's immediate surroundings and those within it, an opportunity to experience complex codes of behavior more universal than that with which one may be familiar, more broadly applicable that would be required by defined social units of family, work or school ${ }^{21}$. In his essay The Strength of Weak Ties, Mark Granovetter suggests that this is foundational to social organizations in general, and for the individual an opportunity to expand social competencies.

\section{INT POPS: VAGUE PROGRAM}

The NYC Zoning Resolution of 1961 resolution emphasized access as the most critical aspect of POPS with regard to its public nature, providing few details illuminating intended purpose or use, outside the passive pursuits implied by the presence of seating. This ambiguity may create its own opportunities; in the absence of behavioral prerogatives driven by programs, inhabitants of INT POPS retain a range of interpretations available to them regarding use. In the absence of the requirement of economic transactions, INT POPS retain the possibility of a range of inhabitants, as the condition of patronage should be understood as a spatial segregator ${ }^{22}$. This further activates the aforementioned opportunities for observation of difference, in the form of the heterogeneous set of everyday negotiations involved in sharing space. These interactions would necessarily lie outside the hierarchies and specializations codified in either more permanent or formal relationships, or vis-à-vis the expectations engendered by program. Mark Granovetter cites the work of Rose Coser, a professor of sociology at SUNY Stony Brook. It was Coser's assertion that in negotiations with strangers, one is required to put oneself in imagination in the position of each role partner in relation to all others, including oneself ${ }^{23}$, an inversion of Arendt's assertion that interactions reveal one's unique distinctness. Coser's interpretation of those exchanges suggest enacted empathy would be required in a range of behaviors, up to and including verbal exchange. Coser's work in role theory suggested that everyday interactions between unrelated individuals required the construction of a temporary provisional status, expanding one's own social repertoire and reinforcing a high level of individualism ${ }^{24}$. One could argue that the ambiguity of the use value of INT POPS require the development of a social agility on the part of its inhabitants. Granovetter goes as far as to suggests that this may be a precondition for the forms of community attachment that support participation in organized protest ${ }^{25}$.

\section{INT POPS: BOUNDED}

To say that INT POPS are bounded is not identical to the conditions of physical enclosure; it is to say that there is an experienced and recognizable unity present within its perceived boundary conditions. Beatriz Colomina asserts that space is a system of representation: individuals present within a bounded space are thus a group, visibly so, in the spirit of Foucault's convenientia ${ }^{26}$. The relationships engendered by occupation are provisional and non-hierarchical, with no implication of permanent ...shared final ends, [] mutual identification and reciprocity ${ }^{27}$, the conditions of community Iris Young posits as a commonly-held critical ideal. The ideal of community denies and represses social difference ${ }^{28}$, and is by its very nature exclusive and anti-urban. Young, in City Life and Difference, suggests

The urban ideal expresses difference as a side-by-side particularity neither reducible to identity nor completely 
other. In this ideal groups do not stand in relations of inclusions and exclusion, but overlap and intermingle without becoming homogeneous. (Young, 1990)

INT POPS construct a temporary condition of the in-common well short of the universalizing characteristics of community, making possible an experience of difference that Young suggests as the legitimate ideal of city life. INT POPS, in their bounded condition, produce the simultaneous conditions of an image of collectivity and the experience of difference.

\section{CRITIQUES \& THEIR CRITIQUES}

A conundrum forms: while serving to support a particular niche of public urban life, INT POPS continue to be very visible (and publicized) examples of the privatization of the public sphere ${ }^{29}$, largely around the issue of obstacles to physical access. Criticism has most commonly emphasized the concrete qualities of a given space which do not permit occupation, often in stark contrast to the conditions required at the time of their construction. These qualities include (but are not limited to) violations regarding hours of operation, lack of ramps and other features permitting access by the disabled, and even appropriations by the state in the name of security $^{30}$. Kayden's project in particular involved an exhaustive and rigorous examination of the encroachment of commercial programs into public zones, often issues of stealth and subtlety, as seating for a private concern may closely resemble that meant for public use; in this case, the vague program that is part of INT POP's spatial praxis can be seen as a vulnerability. What is privileged in the majority of these critiques is emphasis on violations that are visible, demonstrable and enforceable. The critiques limit themselves to that which can be represented with clarity, especially those conditions translatable into language that can be checked against the rules, laws and codes that govern these spaces.

Catherine MacKinnon (citing the work of Kimberlé Crenshaw) posits...intersectionality both notices and contends with the realities of multiple inequalities ${ }^{31}$. Access is of paramount import to any discussion of a space's public nature, but criticism focused on quantitatively demonstrable issues should be qualified with a broader theoretical understanding of behavioral probabilities which by their very nature would leave fewer traces on or in the spaces themselves.

Insufficient signage to identify spaces as public has been cited across critiques ${ }^{32}$. Doug Woodward referred to the problem of the posted signs in INT POPS, both demonstrable in its frank visibility and rather more veiled in the possibilities of their interpretation. As an example, no loitering is not uncommon as a listed restriction, applied to a seating area; this is vague to the point of insensibility. Beyond their precluding an Arendtian public, these open-ended rules are enforced by security guards in the employ of the building management with little to safeguard against an inequitable application of said rule to the space's occupants ${ }^{33}$. Exacerbating these issues are conditions embedded in the aesthetic of these spaces. The majority of NYC midtown INT POPS resemble privatelyowned spaces with public access, programs like commercial or institutional lobbies; indeed, INT POPS occasional share an interior space with adjacent programs serving private concerns and do so as-of-right according to the original agreements which shaped them. The opulence of these spaces are occasionally praised in existing critiques (notably Kayden's), applauding these interiors as civic-minded through showing respect to the public use $\mathrm{e}^{34}$. It is probable, however, that what is welcoming to some may represent a barrier to those with insufficient cultural capita ${ }^{35}$.

Inequitable enforcement of rules, insufficient signage and intimidating aesthetics can be obstacles those excluded by its effects are invisible to those who DO have the capital sufficient for access, to enter and occupy these spaces without fear of harassment or eviction. An emphasis on the clarity of issues of physical access enables public to be defined as simply physically accessible, and serves to occlude those that cannot appear.

\section{CLOSING}

For INT POPS, the stakes for a reexamination of their physical conditions, administration and the modality of their critiques are high. Violations of the zoning regulations continue, as do as-of-right changes ${ }^{36}$ that impact both issues of physical access and users' perceptions. Violations, especially, have enjoyed an uptick in media exposure, due in part to the history of violations at the INT POPS spaces in Trump Tower, but perhaps as much by those spaces' adjacency to the mass protests the Trump election and administration has inspired. Greater clarity beyond the public's right to access these spaces is called for. The conditions generated by INT POPS are not in opposition to the political nor should be devalued because they do not actively support collective action; indeed, Granovetter suggests that those conditions could be understood as foundational to an active political life.

Interior spaces that are vaguely programmed, bounded, enclosed \& enable proximity- these conditions considered simultaneously identify INT POPS and the particular occupations they permit as a unique form of space integral to urban life, an interstitial zone between an actively political public and the so-called tranquility of the social. In order to do so equitably, one needs to assume universal access to these spaces.

This exploration of INT POPS, with its attendant histories and analysis, does not purport to favor either an ideal of a universal public space nor multiple spaces supporting multiple publics; rights to entry supersede these distinctions, as for either (or any combination thereof) the ability to physically occupy any public space is a common denominator. 
Particularly because INT POPS create a bounded representation of an ideal city life, the terrain of existing critiques should be extended to incorporate the more ephemeral effects generated by users' perceptions of these spaces; else the implication remains that the public generated is universal, and that those participating in the construction of that image might be anyone.

This leaves those barred from entry or occupation by other than physical obstacles as invisible, recreating the conditions Arendt ascribed to those exterior to public life.

\section{ENDNOTES}

1. This is the author's proposed term.

2. Intersectionality is term originally defined by legal scholar Kimberlé Crenshaw, a response to ...the problematic consequence of the tendency to treat race and gender as mutually exclusive categories of experience and analysis (Crenshaw, Kimberlé. 1989. "Demarginalizing the Intersection of Race and Sex: A Black Feminist Critique of Antidiscrimination Doctrine." University of Chicago Legal Forum: 139.). It is now commonly understood as an analytic method involving the examination of multiple interlocking systems or characteristics simultaneously.

3. Kayden, Jerold S., New York City Department of City Planning, Municipal Art Society. 2000. Privately Owned Public Space, The New York City Experience. New York: John Wiley and Sons: 33.

4. Significant additions and changes are made in 1968-1973, 1967-1973, 1975, 1977 and 1996 (Kayden, 2000). Amendments in 2007 replaced all previprovided. NYC Planning: Privately Owned Public Space: Current Public Design Standards. Accessed 05.12.18. https://www1.nyc gov/site/planning/plans/ pops/pops-plaza-standards.page

5. Kayden, 2

6. Ibid, 21. Kayden himself admits the obscurity of the zoning language, referring to broad use categories in his own text: destination, neighborhood, hiatus, circulation and marginal (Kayden, 49).

7. Miller, Kristine F. 2007. Designs on the public: The Private Lives of New York's Public Spaces. Minneapolis: University of Minnesota Press: xvi.

8. US Constitution- Amendments to the Constitution-Article [1]. Accessed 02.13.18. http://constitutionus.com/

9. The Supreme Court breaks down forums into three types: traditional public forums, designated forums, and nonpublic forums. (Cornell Law School Lega forums, designated forums, and nonpublic forums. (Cornell Law School Legal edu/wex/forums)

10. Arendt, Hannah, and Margaret Canovan. 1998. The Human Condition. Chicago: University of Chicago Press: 175-181.

11. Woodward, Douglas. 2012. "Writing the City: Rules of Conduct." Accessed 03.20.17. https://urbanomnibus.net/2012/05/rules-of-conduct/.

12. Tehve, Karin. Forthcoming. 2018. "POPS: Access, Appearance and Identity." territories (Ziad Qureshi, Clay Odom, Gregory Marinic, editors): 3.

13. Arendt, 40.

14. Ibid, 68-73.

15. Ibid, 40

16. Habermas, Jürgen, Sara Lennox, and Frank Lennox. "The Public Sphere: An Encyclopedia Article (1964)." New German Critique, no. 3 (1974): 49-55.

17. Lefebvre, Henri. 1991. The Production of Space. Oxford, OX, UK: Blackwell: 38.

18. Sennett, Richard. 2017. "Interiors and Interiority." Interior Matters: SOLID Harvard Symposia on Architecture. Vitoria-Gasteiz: A+T: 10-19.

19. Debord, Guy. 1995. The society of the spectacle. New York: Zone Books: 121.

20. de Solà-Morales, Ignasi. 1995. "Terrain Vague." Anyplace (Cynthia C. Davidson, editor). New York, NY: Anyone Corp. Cambridge, MA: MIT Davidson, editor
Press: $121-122$.

21. Granovetter, Mark. 1983. 'The Strength of Weak Ties: A Network Theory Revisited'. Sociological Theory, Vol. 1. New York: Wiley: 203.

22. Lofland, Lyn H. 1985. A World of Strangers: Order and Action in Urban Public Space. Prospect Heights III: Waveland Press: 73-79.
23. Coser, Rose. 1975. "The Complexity of Roles as Seedbed of Individual Autonomy." The Idea of Social Structure: Essays in Honor of Robert Merton (L. Coser, editor). New York: Harcourt Brace Jovanovich: 257. quoted in Granovetter, 204

24. Ibid.

25. Granovetter, 224

26. Foucault, Michel. 2010. The order of things: an archaeology of the human sciences. London: Routledge: 18

27. Young, Iris Marion. 1990. "City Life and Difference." The People, Place and Space Reader (edited by Jen Jack Gieseking \& William Mangold, with Cindi Katz, Setha Low, \& Susan Saegert). New York: Routledge, Taylor \& Francis Katz, Setha Low,
Group, 2014: 249 .

28. Ibid, 247.

29. Kayden, 2000; Miller, 2007; Woodward, 2012; Also: Stringer, Scott (New York City Comptroller). 2017. "Audit Report on the City's Oversight over Privately Owned Public Spaces." Accessed 05.20.17. http://comptroller.nyc.gov/ reports/audit-report-on-the-on-the-citys-oversight-over-privately-ownedpublic-spaces.

30. Miller, 2007; Stringer, 2017.

31. MacKinnon, Catharine A. 2013. "Intersectionality as Method: A Note." Signs, Vol. 38: No. 4. Intersectionality: Theorizing Power, Empowering Theory. Chicago: The University of Chicago Press. 1019.

32. Kayden, 2000; Miller, 2007; Woodward, 2012; Stringer, 2017

33. Tehve, 4.

34. There a number of references to this in the text. An example, in reference to the INT POPS at 145 West $44^{\text {th }}$ Street, Millennium Broadway: The positive side of this private-public merger is that there is no stinting on quality, no secondclass treatment of public space (Kayden, 132).

35. Tehve, 4

36. Stringer, 2017. 